\title{
Dynamics of Financial Disadvantage
}

\section{Gary Marks}

$\mathrm{R}$ esearch on financial disadvantage in Australia has focused mainly on income poverty. Income poverty is defined as living in a household whose income is below that of a designated poverty line. However, income poverty may provide only a limited understanding of financial disadvantage. Concepts such as subjective poverty, expenditure poverty, deprivation and financial stress are designed to overcome perceived inadequacies in the concept of income poverty. A major point of the submission by the Department of Family and Community Services (DFCS, 2003:xi) to the Senate (2004:xvii,18-20) inquiry into poverty was that financial disadvantage was too narrowly defined by income. Deprivation and financial stress are measures of households' financial situation that may complement income poverty (McColl, Pietsch and Gatenby, 2001). Saunders (1996) pointed out that income is at best an imperfect indicator of living standards. Travers and Richardson (1993) argued that financial disadvantage is better measured by several indicators, such as deprivation and financial stress, as well as income. Therefore, there is an implicit assumption that the different indicators are tapping the same underlying concept of poverty or financial disadvantage, but all do so imperfectly.

The purpose of this paper is to contribute to the understanding of financial disadvantage by analysing several of its indicators in addition to the commonly used measure, before-housing income poverty. The additional indicators are afterhousing income poverty, subjective poverty and financial stress. The paper examines the extent of financial disadvantage in Australia according to these four indicators, mobility in and out of financial disadvantage, and the interrelationships between indicators. The relationships between the indicators and a range of demographic, sociological and economic factors are also examined.

Before-housing Income poverty is defined as living in a household with disposable income, after adjusting for household composition, below a designated poverty line. After-housing measures adjust household disposable income and thus the designated poverty line for housing costs. Subjective poverty is defined as judging one's level of prosperity as 'poor' or 'very poor'. Individuals and households in financial stress are not coping financially; they have difficulty in meeting their financial obligations and may seek financial assistance from others.

Income poverty, subjective poverty and financial stress are by no means the only indicators of financial disadvantage. Other indicators include expenditure poverty which, similar to income poverty, is defined as expenditure levels less than a designated level (DFCS, 2003:92; Saunders, 1997; Saunders, 1998); relative deprivation, defined as the 'enforced lack of perceived social necessities

Gary N. Marks is Research Associate and Associate Professor at the Melbourne Institute of Economic and Social Research. 
in life' (Mack and Lansley, 1985:39); multidimensional approaches which combine several measures of poverty (Dewilde, 2004; Kangas and Ritakallio, 1998); and the social exclusion approach which broadens the concept of poverty to include social relationships and participation (Eurostat Task Force, 1998; Saunders and Kayoko, 2002:45-62; Tsakloglou and Papadopoulos, 2002; Whelan, Layte and Maitre, 2003).

However, due to data limitations this study is restricted to income poverty, subjective poverty and financial stress.

\section{Previous Studies}

\section{Incidence}

The dominant approach to the study of poverty in Australia and in other western countries is relative income poverty. The poverty line is most often drawn at half the median disposable household income (Atkinson, 1998; Brady, 2003; Moller et al, 2003; Oxley, 1997). Using the commonly used OECD equivalence scale to adjust for household size the half-median disposable income measure indicates that about 10 per cent of Australians were in poverty in 2000 (Harding, Lloyd and Greenwell, 2001:35). For the financial year, 2000-2001 the estimate by Headey, Marks and Wooden, (2005) is much higher at 14 per cent - the discrepancy is probably due to differences in the processing of households with very low, zero or negative incomes. After adjusting for housing costs, Harding, Lloyd and Greenwell (2001:36) found income poverty increased by 5 percentage points to around 15 per cent.

The measurement of non-income concepts such as subjective poverty and financial stress is less common in Australia and often varies between survey instruments. The 1998-99 Household Expenditure Survey included items that are often used as indicators of financial stress. About 16 per cent of households could not pay utility bills on time, 7 per cent could not pay car registration or insurance on time, 4 per cent pawned or sold something, 3 per cent went without meals, 2 per cent could not afford to heat their home and 3 per cent sought assistance from welfare organizations. A summary measure of financial stress indicated that about 13 per cent of households had high levels of financial stress, 21 per cent moderate stress and 66 per cent low or no stress (ABS, 2002; McColl, Pietsch and Gatenby, 2001).

\section{Dynamics}

Only recently has it been possible to study the dynamics of income poverty in Australia. Breusch and Mitchell (2003) reported that of households in the lowest equivalised income quintile in 1997, only 29 per cent were in the same quintile three years later. In a study of child poverty dynamics in Australia, Abello and Harding $(2004: 18,33)$ estimated that about 5 to 7 per cent were poor persistently over a three-year period. About 30 per cent were in poverty in one of the three 
years examined (p. 20). More recently, analysis of the first three waves of the Household, Income and Labour Dynamics in Australia (HILDA) survey estimated that about four per cent were in poverty (defined as below 50 per cent of median household income) consistently compared to annual rates of between 12 and 14 per cent (Headey, Marks and Wooden, 2005).

\section{Inter-relationships between indicators of financial disadvantage}

The relationships between income poverty and other indicators of financial disadvantage tend to be weaker than expected. Financial stress is higher among households in the lowest income quintile, and declines in each subsequent quintile. However, 70 per cent of households in the lowest income quintile had no cashflow problems in the previous twelve months (ABS, 2004:Table 32). Bray (2003:vi,23) noted that although lower incomes are associated with higher rates of financial stress, only a minority of households in the lowest income quartile experienced hardship or cash-flow problems. Generally, the correspondence between income poverty and other measures of financial disadvantage is not high. Saunders, Brashaw and Hirst (2002) found the poverty rate in the United Kingdom was halved when defined in terms of both income and expenditure. In Australia, only about 2.2 per cent of households were in both income and expenditure poverty. Bradshaw and Finch (2003) found only a weak correspondence between subjective evaluations on being in poverty and income poverty.

\section{Demographic and sociological correlates of financial disadvantage}

Most of the Australian research on the correlates of financial disadvantage has focused on income poverty. Income poverty is lower among older Australians especially on post-housing measures (Harding, Lloyd and Greenwell, 2001:17, 19; Korpi and Palme, 1998; Saunders, 1996). Harding, Lloyd and Greenwell (2001) found no substantial differences by gender in the risk of being in poverty. According to the Australian Institute of Health and Welfare, poverty among sole parents in 1989-90 was about three times the national rate (Saunders, 1996). Similarly, Harding, Lloyd and Greenwell, (2001) estimated that 22 per cent of sole parents were in poverty, compared to 18 per cent of single persons, 12 per cent of couples with children and only 6 per cent of couples without children. Among sole parents with two or more children the poverty rate is over 25 per cent (pp. 7-8). Eardley (1998) also found that income poverty is associated with sole parenthood and larger families. Poverty among Indigenous Australians is very high; about three times the rate among non-indigenous families (Ross and Whiteford, 1992). Overall, immigrants do not show a particularly high incidence of poverty although some immigrant groups do (Johnson 1991). Low education is also associated with income poverty. Among those with no post-secondary qualifications, income poverty (on the half mean disposal income measure) was 15 per cent compared to 11 per cent among those with diploma, certificate and trade qualifications and only 6 per cent among those with a Bachelor degree (or higher) qualification (Harding, Lloyd and Greenwell, 2001:14). Income poverty is 
strongly associated with labour force status. Among families with no wage earners, 28 per cent were in poverty in 2000 compared to less than seven per cent of families with at least one full-time wage earner (Harding, Lloyd and Greenwell, 2001:12). Eardley (1998) found that among full-year full-time employees, poverty, defined by the half median income, was very low at around one per cent.

Work on social correlates of other financial disadvantage indicators is limited to financial stress. Breunig and Cobb-Clark (2004) found that sole parenthood and children are associated with financial stress. La Cava and Simon (2005) reported that 'cash flow problems' were negatively related to age, being a couple without children, home ownership (and home value), disposable income and number of credit cards held, and was positively related to unemployment, family size, single parenting, and being on welfare. McColl, Pietsch and Gatenby (2001) found that financial stress was associated with larger families, disability, sole parenthood, unemployment, having a mortgage, and paying interest on credit cards.

\section{Data and Measures}

\section{Data}

The data used in these analyses are from the first three waves (2001 to 2003) of the longitudinal Household, Income and Labour Dynamics in Australia (HILDA) survey. Several features of HILDA make it particularly useful for investigations of financial disadvantage. It is the first large-scale Australian longitudinal survey of adults specifically designed to investigate dynamics, whereas previous studies of poverty have relied on cross-sectional data. Second, income data were collected from all available (and eligible) household members, improving the accuracy of income and other variables. Third, HILDA includes data from wave 2 on wealth, assets and debts allowing for the examination of their relationships with financial disadvantage. The HILDA Users Manual (Watson, 2005) details the sampling, weighting, imputation and other technical aspects of the study.

For each wave, three data files were created: a household data file derived from the household questionnaire, a responding person file derived from the person questionnaire and the self-completion questionnaire. The enumerated person data file was derived from the household grid. The questionnaires can be downloaded from the Melbourne Institute web-site.

\section{Measures}

The four measures of financial disadvantage measured are: housing income poverty, after-housing income poverty, subjective poverty and financial stress. Individuals living in a household with equivalised disposable income below 50 per cent of the median were defined as before-housing income poverty. Income includes income from wages and salary, unincorporated businesses, investments, private pensions (superannuation, workers' compensation), government benefits and pensions, and other regular sources (for example, child maintenance 
payments). Disposable income is calculated as the income received after adjusting for taxes and government transfers such as pensions, family benefits, unemployment and other benefits (Headey, 2003). Where information on any of the main income components was missing, its value was imputed using a method developed specifically for longitudinal data (see Watson, 2005). The equivalence scale used is the modified OECD scale which assigns a weight of 1 to the first adult, a weight of 0.5 to second and other adults and a weight of 0.3 for children under 14 years of age (Förster, 2000; OECD 2001:note 2; Whelan, Layte, and Maitre, 2002). The resulting measure differs slightly from other measures of before-housing income poverty constructed from the HILDA data. The poverty line is drawn at the household with the median income, not the household that includes the individual with the median income. Second, households with negative household incomes were not included in the calculation of income poverty.

The second measure - after-housing income poverty - is similar to the first. Following Harding, Lloyd and Greenwell, (2001) disposable family income has been recalculated by subtracting housing costs. From this distribution a second income poverty line was calculated at 50 per cent of the median. The third measure subjective poverty was defined by respondents indicating that they were 'poor' or 'very poor' in response to a question on their level of prosperity. Respondents were asked: 'Given your current needs and financial responsibilities, would you say you and your family are' (Prosperous, Very Comfortable, Reasonably Comfortable, Just Getting Along, Poor, and Very Poor). The fourth measure, 'financial stress', is defined in terms of seven behaviours due to $a$ shortage of money: could not pay utility bills on time, could not pay mortgage or rent on time, pawned or sold something, went without meals, was unable to heat home, asked for financial help from friends or family, and asked for help from welfare/community organisations. Individuals were defined as in financial stress if they experienced two or more of these events since the beginning of the year. One cash-flow problem, such as not paying a pay on time or borrowing money does not really constitute financial stress since there many reasons why this may occur. However, two or more cash-flow problems do suggest financial stress.

\section{Findings}

\section{The extent of financial disadvantage}

Table 1 presents estimates of the level of financial disadvantage according to the four indicators. The estimates are for each wave and weighted with the responding person weights. The standard errors (in parentheses) allow calculation of confidence limits for the estimates. These standard errors are adjusted for the clustering of individuals within households. The commonly used 95 per cent confidence limits are plus or minus 1.96 (or 2) standard errors of the estimate. The weights take into account differences between the samples and population benchmarks and to adjust for sample attrition. 
The four measures provide quite different estimates of the level of financial disadvantage. The level of subjective poverty is low at 4.3 per cent. Since the standard error is 0.4 per cent, the 95 per cent confidence limits for the incidence of subjective poverty is between 3.5 and 5.1 per cent (that is, $4.3 \pm 2 * 0.4$ ). In contrast, the level of financial stress is fairly high between 14 and 17 per cent. Before-housing income poverty was between 11 and 13 per cent. The afterhousing measure shows a higher incidence of income poverty: nearly 16 per cent in wave 1 and 13 per cent in wave 3 . Higher levels of poverty using the posthousing measure were also found by Harding, Lloyd and Greenwell, (2001:35-36). Although the incidence of financial disadvantage on any one indicator for a single year is generally low, the incidence for any one of the three years is substantially higher. A quarter was in before-housing income poverty in at least one of the three years, 30 per cent on the after-housing measure; 10 per cent judged themselves as 'poor' or 'very poor' in at least one of the 3 years and 32 per cent had some experience of financial stress. Overall, 53 per cent had experienced financial disadvantage on any indicator in at least one of the three years.

Table 1: Financial Disadvantage Measures: Australia, Persons over 18

\begin{tabular}{l|rrrr}
\hline Indicator & Wave 1 & Wave 2 & Wave 3 & Any Wave \\
\hline & \multicolumn{5}{|c}{ per cent (standard error) } \\
Before-Housing Income poverty & $12.6(0.4)$ & $11.6(0.4)$ & $10.8(0.4)$ & $25.0(0.6)$ \\
After-Housing Income poverty & $15.6(0.5)$ & $14.8(0.5)$ & $13.3(0.5)$ & $29.5(0.6)$ \\
Subjective Poverty & $4.3(0.2)$ & $3.9(0.2)$ & $3.7(0.2)$ & $10.7(0.4)$ \\
Financial Stress (2 or more instances) & $17.1(0.4)$ & $14.6(0.4)$ & $14.0(0.4)$ & $32.0(0.6)$ \\
\hline
\end{tabular}

Note: Standard errors adjusted for clustering of individuals within households.

Table 2: Year-to-Year Stability of Financial Disadvantage

\begin{tabular}{l|ccc}
\hline State in Wave 1 & \multicolumn{3}{|c}{ Same State in } \\
& Wave 2 & Wave 3 & Waves 2 \& 3 \\
\hline Income Poverty (Before Housing) & \multicolumn{3}{|c}{ per cent (standard error) } \\
Income Poverty (After Housing) & $45.7(1.7)$ & $42.1(1.8)$ & $24.0(1.5)$ \\
Subjective Poverty & $47.7(1.6)$ & $43.0(1.6)$ & $29.8(1.5)$ \\
Financial Stress (2 or more instances) & $42.1(2.8)$ & $30.0(2.6)$ & $21.4(2.5)$ \\
\hline
\end{tabular}

Note: Standard errors adjusted for clustering of individuals within households.

\section{The persistence of financial disadvantage}

Table 2 shows there is only a moderate degree of persistence of financial disadvantage over time. As for the preceding analyses the unit of analysis is the 
individual and weighting is based on the responding person weight for the first wave. Of those in before-housing income poverty in wave 1, about 46 per cent were in poverty, so defined, in wave 2, 42 per cent in wave 3 and less than quarter in waves 2 and 3 . Therefore, only 3 per cent were in before-housing income poverty in all three waves. The persistence of after-housing income poverty was slightly higher, but only 5 per cent were in post-housing income poverty in all three waves. Similarly, there was little year-to-year persistence in subjective poverty. Of those who indicated they were poor or very poor in wave 1,42 per cent were in subjective poverty in wave 2, 30 per cent in wave 3 and only about 20 per cent in both waves 2 and 3 . Therefore, less than 1 per cent defined themselves as 'poor' or 'very poor' every year. The year-to-year persistence of financial stress was higher than that for the other indicators of financial disadvantage. Of those in financial stress in wave 1, a majority (55 per cent) were in financial stress in wave 2, 49 per cent in wave 3 but only 36 per cent in waves 2 and 3 . Therefore, about 6 per cent of adults were in financial stress in all three waves.

\section{Correspondence among indicators of financial disadvantage}

The correspondence between the indicators of financial disadvantage at the same time point does not seem to be strong (Table 3 ). These analyses are also based on individuals weighted with the appropriate responding person weight for that wave.

Table 3: Correspondence Between Financial Disadvantage Indicators

\begin{tabular}{l|cccc}
\hline Indicator & 1 & 2 & 3 & 4 \\
\hline Wave 1 & \multicolumn{4}{|c}{ per cent (standard error) } \\
1 Before-housing income poverty & - & $80.9(1.3)$ & $10.5(0.9)$ & $26.3(1.3)$ \\
2 After-Housing Income poverty & $65.0(1.5)$ & - & $11.4(0.9)$ & $31.3(1.3)$ \\
3 Subjective Poverty & $29.7(2.3)$ & $40.7(2.6)$ & - & $68.0(2.5)$ \\
4 Financial Stress & $18.7(1.0)$ & $28.0(1.2)$ & $16.9(0.9)$ & - \\
Wave 2 & & & & \\
1 Before-housing income poverty & - & $78.2(1.4)$ & $9.3(1.0)$ & $23.4(1.5)$ \\
2 After-Housing Income poverty & $61.6(1.8)$ & - & $10.2(1.0)$ & $28.1(1.4)$ \\
3 Subjective Poverty & $25.8(2.5)$ & $35.1(2.8)$ & - & $65.4(2.7)$ \\
4 Financial Stress & $17.5(1.2)$ & $26.3(1.4)$ & $17.4(1.1)$ & - \\
Wave 3 & & & & \\
1 Before-housing income poverty & - & $76.8(1.6)$ & $9.2(1.1)$ & $23.2(1.6)$ \\
2 After-Housing Income poverty & $62.4(1.9)$ & - & $10.2(1.0)$ & $29.9(1.7)$ \\
3 Subjective Poverty & $25.2(2.7)$ & $35.3(3.0)$ & - & $65.6(2.9)$ \\
4 Financial Stress & $16.8(1.2)$ & $27.2(1.5)$ & $17.1(1.2)$ & - \\
\hline
\end{tabular}

Note: Percentages are proportions of each group listed on the left hand side. Standard errors adjusted for clustering of individuals within households. Diagonals $=100$ per cent. 
The correspondence between income poverty and the two non-income measures of financial disadvantage is surprisingly weak. Of those in 'beforehousing income poverty', only about 10 per cent indicated they were 'poor' or 'very poor' and between 20 or 30 per cent were in financial stress. The association between income poverty and financial stress was somewhat stronger on the after-housing measure than before-housing of income poverty. Of those who indicated they were 'poor' or 'very poor', fewer than 30 per cent were in before-housing income poverty and less than 40 per cent were in poverty on the post-housing measure. The relationship between subjective poverty and financial stress is stronger. Of those in subjective poverty, about two-thirds were in financial stress. However, only 17 per cent of those in financial stress judged their financial circumstances as 'poor' or 'very poor'.

Stronger relationships are found between the two measures of income poverty. Of those in before-housing income poverty about 80 per cent were also in after-housing income poverty. However, the correspondence in the other direction is much weaker. Of those in after-housing income poverty only 60 to 65 per cent were in before-housing income poverty.

\section{Correlates of financial disadvantage}

Table 4 presents the results from logistic regression analysis of the four measures of financial disadvantage with a range of demographic, socioeconomic and educational factors. The analyses are limited to adults aged 18 or older. To avoid problems with statistical independence when two or more adults are from the same household, one adult household member was randomly selected from each household. Therefore, the weights used were the household weights. In the text following, the logistic coefficients in Table 4 are converted to odds ratios, which are the exponents of the coefficients. For categorical variables - gender, Indigenous status, language background, type of school attended, education, and marital status - the effects are relative to the appropriate contrast group females, the non-Indigenous, an English speaking background, attended a government school, highest education level Year 12, and single and never married. So the interpretation of the odds ratio is relative to the contrast group, for example, the odds of men being in income poverty are so many times the odds for women, the odds of being in poverty for married persons is so many times that for single people etcetera. The interpretation of the effects for continuous variables depends on the unit of measurement. Here, the number of siblings and number of children are continuous variables ranging from zero. Therefore, the coefficients of these variables are the effects on being in financial disadvantage for a one unit change, that is, for one additional sibling or child. For two siblings or two children the effects are doubled and the odds ratios are squared. Similarly, the effects for three siblings or three children are three times the effects for one sibling or child and the odds ratios are cubed. Age has been divided by 10 so the effects are the change in the odds of being in poverty for a 10 year difference in age. Similarly, both 
parental and respondents' occupational status has been divided by 10 so that effects are for a 10 unit difference on the zero to 100 occupational status scale.

Table 4: Relationships of Financial Disadvantage with Demographic, Socioeconomic and Educational Correlates

\begin{tabular}{l|cccc}
\hline & $\begin{array}{c}\text { Before-Housing } \\
\text { Income poverty }\end{array}$ & $\begin{array}{c}\text { After-Housing } \\
\text { Income poverty }\end{array}$ & $\begin{array}{c}\text { Subjective } \\
\text { Poverty }\end{array}$ & $\begin{array}{c}\text { Financial } \\
\text { Stress }\end{array}$ \\
\hline Intercept & $-1.22^{* * *}$ & $-0.94^{* * *}$ & $-2.79^{* * *}$ & $-1.71^{* * *}$ \\
Male & $-0.19^{*}$ & $-0.19^{* *}$ & 0.20 & -0.03 \\
Age & $0.19^{* * *}$ & -0.02 & -0.08 & $-0.56^{* * *}$ \\
Number of Siblings & $0.03^{*}$ & $0.03^{* *}$ & 0.03 & $0.06^{* * *}$ \\
Not with Both Parents at Age 15 & 0.17 & 0.08 & 0.23 & 0.15 \\
$1^{\text {st }}$ Language not English & $0.70^{* * *}$ & $0.74^{* * *}$ & $0.52^{* * *}$ & $0.28^{* *}$ \\
Indigenous & $0.49^{*}$ & 0.28 & 0.05 & 0.26 \\
Parental Occ. Status (10s) & -0.01 & 0.00 & 0.02 & 0.00 \\
Catholic School & -0.18 & $-0.20^{*}$ & -0.17 & -0.03 \\
Independent School & 0.16 & 0.08 & 0.01 & 0.04 \\
Post-Graduate Quals & $-1.43^{* * *}$ & $-1.01^{* * *}$ & $-0.80^{* *}$ & $-1.10^{* * *}$ \\
Bachelor Degree & $-0.85^{* * *}$ & $-0.67^{* * *}$ & -0.30 & $-0.46^{* *}$ \\
Diploma & -0.30 & -0.22 & -0.07 & -0.03 \\
Advanced Certificate & -0.09 & -0.16 & 0.41 & 0.21 \\
Certificate & -0.17 & -0.07 & 0.25 & $0.29^{*}$ \\
<Year 12 & 0.18 & 0.11 & $0.45^{* *}$ & $0.44^{* * *}$ \\
Married & $-1.48^{* * *}$ & $-1.41^{* * *}$ & $-1.76^{* * *}$ & $-1.29^{* * *}$ \\
De facto & $-1.26^{* * *}$ & $-1.04^{* * *}$ & $-0.92^{* * *}$ & $-0.49^{* * *}$ \\
Separated & $-0.48^{* *}$ & -0.24 & -0.23 & 0.11 \\
Divorced & $-0.41^{* *}$ & $-0.48^{* * *}$ & 0.14 & $0.26^{*}$ \\
Widowed & $-0.38^{* *}$ & $-0.52^{* * *}$ & $-1.74^{* * *}$ & $-0.81^{* * *}$ \\
Number of Children & $0.13^{* * *}$ & $0.16^{* * *}$ & $0.15^{* * *}$ & $0.24^{* * *}$ \\
Rescaled R Square & 0.17 & 0.12 & 0.12 & 0.24 \\
\hline & & & & \\
\hline
\end{tabular}

Note: $* * * \mathrm{P}<0.001, * * 0.001<\mathrm{P}<0.01, * 0.01<\mathrm{P}<0.05$.

Source: HILDA Wave 1.

Consistent with the low correspondence between the four measures of financial disadvantage is their distinctive relationships with background factors. The odds of women being in income poverty were about 1.2 times that for men but there were no gender differences with subjective poverty and financial stress.

Before-housing income poverty is more common among older persons; but there were no statistically significant age differences on the after-housing measure and younger cohorts were substantially more likely to be in financial stress. Further analyses showed that financial stress is highest in the youngest cohort, and declines in successively older cohorts. The number of siblings, not living with 
both parents at age 15, parental occupational status and type of school attended all have weak or statistically insignificant relationships with financial disadvantage. In contrast, a first language other than English increased the odds of financial disadvantage on all four indicators: quite substantially for income poverty. Indigenous status increased the odds of before-income housing poverty but its effects on the other indicators were not statistically significant.

Post-graduate and bachelor degrees substantially reduce the chances of financial disadvantage. However, the strength of these effects of education varied with indicator and a bachelor degree had no impact on subjective poverty. Compared with completion of Year 12, bachelor degrees reduce the odds of before-housing income poverty 2.3 times, post-housing income poverty 2.0 times, and financial stress 1.6 times. Not completing school (Year 12) increased the odds of subjective poverty and financial stress by about 1.5 times. In contrast, diplomas and certificates did not reduce the odds of financial disadvantage. Certificates actually increased the odds of financial stress.

Table 5: Economic Characteristics of Disadvantaged Households

\begin{tabular}{|c|c|c|c|c|c|c|c|c|}
\hline & \multicolumn{2}{|c|}{$\begin{array}{c}\text { Pre-Housing } \\
\text { Income poverty }\end{array}$} & \multicolumn{2}{|c|}{$\begin{array}{l}\text { Post-Housing } \\
\text { Income poverty }\end{array}$} & \multicolumn{2}{|c|}{$\begin{array}{l}\text { Subjective } \\
\text { Poverty }\end{array}$} & \multicolumn{2}{|c|}{ Financial Stress } \\
\hline & Yes & No & Yes & No & Yes & No & Yes & No \\
\hline Means & \multicolumn{8}{|c|}{$\${ }^{\prime} 000$} \\
\hline Personal Income & 7.8 & 38.4 & 11.5 & 38.7 & 21.4 & 35.3 & 25.5 & 36.2 \\
\hline Personal Disposable Income & 7.0 & 29.2 & 9.7 & 29.4 & 17.6 & 26.9 & 20.6 & 27.5 \\
\hline Household Income & 9.7 & 70.1 & 16.1 & 70.7 & 33.4 & 63.9 & 39.6 & 66.6 \\
\hline $\begin{array}{l}\text { Equivalised Household (HH) } \\
\text { Income }\end{array}$ & 8.6 & 53.6 & 13.5 & 54.0 & 28.0 & 48.8 & 32.1 & 50.8 \\
\hline $\begin{array}{l}\text { Equivalised Disp. HH } \\
\text { Income }\end{array}$ & 5.5 & 32.3 & 8.2 & 32.6 & 18.6 & 29.5 & 20.1 & 30.6 \\
\hline $\begin{array}{l}\text { Equiv Disp. HH Income } \\
\text { after Housing }\end{array}$ & 2.2 & 27.6 & 2.1 & 28.4 & 13.7 & 25.0 & 14.9 & 26.3 \\
\hline Household Wealth & 252.2 & 450.8 & 223.5 & 462.1 & 103.3 & 447.6 & 158.4 & 479.5 \\
\hline Household Assets & 280.1 & 527.0 & 270.0 & 536.2 & 124.2 & 519.7 & 200.6 & 554.2 \\
\hline Household Debt & 31.0 & 76.4 & 45.2 & 75.0 & 23.6 & 72.8 & 46.4 & 75.0 \\
\hline Medians & \multicolumn{8}{|c|}{$\$ \cdot 000$} \\
\hline Personal Income & 10.0 & 30.5 & 10.8 & 30.8 & 14.8 & 27.2 & 21.8 & 28.0 \\
\hline Personal Disposable Income & 9.9 & 24.5 & 10.7 & 24.7 & 14.6 & 22.3 & 19.2 & 22.6 \\
\hline Household Income & 11.4 & 57.3 & 13.6 & 58.8 & 25.6 & 51.9 & 33.1 & 54.8 \\
\hline $\begin{array}{l}\text { Equivalised Household (HH) } \\
\text { Income }\end{array}$ & 11.3 & 45.2 & 13.5 & 46.2 & 22.8 & 41.7 & 27.8 & 43.6 \\
\hline $\begin{array}{l}\text { Equivalised Disposable } \mathrm{HH} \\
\text { Income }\end{array}$ & 10.1 & 27.8 & 11.0 & 28.2 & 14.9 & 25.6 & 17.6 & 26.7 \\
\hline $\begin{array}{l}\text { Equiv Disposable HH Income } \\
\text { after Housing }\end{array}$ & 6.5 & 23.2 & 6.5 & 23.7 & 11.1 & 21.4 & 12.9 & 22.5 \\
\hline Household Wealth & 103.9 & 261.5 & 42.6 & 272.4 & 25.1 & 258.5 & 48.3 & 290.5 \\
\hline Household Assets & 119.5 & 339.0 & 59.0 & 346.0 & 35.0 & 332.0 & 76.2 & 359.1 \\
\hline Household Debt & 0.0 & 18.0 & 1.7 & 16.0 & 3.7 & 13.0 & 10.0 & 13.0 \\
\hline
\end{tabular}


One striking finding from these analyses is the protective role of marriage and to a lesser extent de facto relationships. Compared to the 'single and nevermarried' group, marriage reduces the odds of financial disadvantage by between 3.6 and 4.0 times. Part of its effect is because there is a second adult who can provide income greater than the expenditure required. However, the benefits of marriage appear to be more than just two incomes since it has strong effects on both subjective poverty and financial stress. Additional analyses showed that the effects for marriage and de facto relationship were not substantially reduced when controlling for household disposable income and wealth as well as the variables listed in Table 4 (available from the author). Therefore, it appears that marriage is associated with a set of attitudes and behaviours that reduces financial disadvantage. De facto relationships also reduced the odds of financial disadvantage and the effects of being separated, divorced and widowed varied substantially with indicator. The number of children increased the odds of financial disadvantage, especially for financial stress.

Table 5 presents the means and medians of several measures of income and wealth for the groups defined as 'in', and 'not in', financial disadvantage in wave 3. The unit of analysis was the individuals randomly selected for the analyses presented in Table 4 and weighted with the household weights. Again these factors have different relationships with the indicators of financial disadvantage. The groups in income poverty have by definition low incomes but relatively high wealth compared to the subjective-poverty and financial stress groups. In contrast, the latter two groups have higher incomes. The subjective-poverty group have the lowest mean and median levels of wealth. The financial stress group have larger debt than the other three groups.

\section{Discussion}

Estimates of the extent of financial disadvantage in Australia vary enormously depending on the way in which it is defined. At one extreme more than half have had some experience of financial disadvantage over the three year period. At the other extreme, the proportion that were experiencing financial disadvantage every year on each single indicator is about 5 per cent or less. Similarly, the correspondence between income-based and other measures of financial disadvantage is low. The majority of those in income poverty do not see themselves as poor or experience financial stress. Furthermore, these indicators of financial disadvantage pertain to different sections of Australian society although both education and partnering provide substantial protection against financial disadvantage. So although many experience some form of financial disadvantage at some time, the proportion financially disadvantaged persistently over a three year period on two or more indicators is very small. These findings challenge the traditional understanding that there is a readily identifiable and sizable group of poor Australians, which consistently have low incomes, see themselves as poor and continually experience financial stress. 
Although measures of before-housing income poverty are often used in research on poverty, care should be taken with its use. For example, the beforehousing measure indicates higher poverty among older persons. However, this is likely to be misleading since sizable proportions of older persons have little or no housing costs so have relatively high discretionary incomes. On the after-housing measure there is no relationship with age. In contrast, younger cohorts are more likely to be experiencing financial stress.

An initial understanding is that subjective poverty and financial stress are both indicators of poverty that when combined with measures of income poverty would more accurately define 'true' poverty or disadvantage. However, they appear not to be indicators of the same underlying concept. For a start, their correspondence is not as strong as expected if they were indicators of the same concept. Furthermore, their relationships with social background, demographic, education and economic variables are in many instances different. Income poverty is about having an income less than that defined by the poverty line. Households experiencing income poverty do not have particularly high levels of debt. In contrast, subjective poverty is a judgement of one's level of prosperity, which is much less associated with education, and more strongly associated with wealth. It is a psychological judgement which probably involves a range of other factors such as type and standard of housing, the area of residence, networks and future prospects. Financial stress is about shortages of cash. It is much more strongly associated with age and the number of children than either income poverty or subjective poverty. A shortage of cash may be because of inexperience in the management of expenses (or lack of financial literacy especially among young people), large debts, and unforeseen expenses. It is possible to have a moderate or even high household income and experience financial stress. Therefore, these three aspects of financial disadvantage are quite distinct concepts and should be understood as such.

\section{References}

Abello, A. and A. Harding (2004), 'The Dynamics of Child Poverty in Australia', National Centre for Social and Economic Modelling, University of Canberra, Canberra.

Australian Bureau of Statistics (2002), 'Income and Welfare - Household Income, Living Standards and Financial Stress', (Cat. No. 1301.0 2002), Canberra.

Australian Bureau of Statistics (2004), 'General Social Survey: Summary Results, Australia Tables', Canberra.

Atkinson, A. (1998), Poverty in Europe, Blackwell, Oxford.

Australian Senate (2004), 'A Hand Up Not a Hand Out: Renewing the Fight Against Poverty', Community Affairs Reference Committee, Canberra.

Bradshaw, J. and N. Finch, (2003), 'Overlaps in Dimensions of Poverty', Journal of Social Policy 32(4):513-25.

Brady, D. (2003), 'Rethinking the Sociological Measurement of Poverty', Social Forces 81(3):715-52. 
Bray, R. (2003), 'Hardship in Australia: An Analysis of Financial Stress Indicators in the 1998-99 Australian Bureau of Statistics Household Expenditure Survey', Department of Family and Community Services, Canberra.

Breunig, R. and Cobb-Clarke, D. (2004), 'Understanding the Factors Associated with Financial Stress in Australian Households.' The Australian National University, Canberra, mimeo.

Breusch, T. and D. Mitchell (2003), 'Australian Family Income Dynamics: Preliminary Evidence from the NLC Project 1997 \& 2000', 8th Australian Institute of Family Studies Conference, Melbourne.

Department of Family and Community Services (2003), 'Inquiry into Poverty and Financial Hardship', Canberra.

Dewilde, C. (2004), 'The Multidimensional Measurement of Poverty in Belgium and Britain: A Categorical Approach', Social Indicators Research 68(3):331-370.

Eardley, T. (1998), 'Working but Poor? Low Pay and Poverty in Australia', Social Policy Research Centre, University of New South Wales, Sydney.

Eurostat Task Force (1998), 'Recommendation on Social Exclusion and Poverty Statistics. Document CPS/98/31/2', Luxembourg: Statistical Office of the European Communities.

Förster, M. (2000), 'Trends and Driving Factors in Income Distribution and Poverty in the OECD Area', Labour Market and Social Policy Occasional Papers No. 42, OECD, Paris.

Harding, A., R. Lloyd and H. Greenwell (2001), 'Financial Disadvantage in Australia, 1990-2000: The Persistence of Poverty in a Decade of Growth', The Smith Family, Camperdown, NSW.

Headey, B. (2003), 'How Best to Impute Taxes and Measure Public Transfers?', Melbourne Institute for Applied Economic and Social Research, University of Melbourne.

Headey, B., G. Marks and M. Wooden, (2005), 'The Dynamics of Income Poverty in Australia: Evidence from the First Three Waves of the HILDA Survey', Australian Journal of Social Issues 40(4).

Johnson, D. (1991), 'The Measurement and Extent of Poverty among Immigrants', Bureau of Immigration Research, Canberra.

Kangas, O. and V. Ritakallio (1998), 'Different Methods-Different Results? Approaches to Multidimensional Poverty', pp. 167-203 in H. Andress (ed.) Empirical Poverty Studies, Ashgate, Aldershot.

Korpi, W. and J. Palme (1998), 'The Paradox of Redistribution and Strategies of Equality: Welfare Institutions, Inequality and Poverty in the Western Countries', American Sociological Review 63(5):661-687.

La Cava, G. and J. Simon (2005), 'Household Debt and Financial Constraints in Australia', Australian Economic Review 38(1):40-60.

Mack, J. and S. Lansley (1985), Poor Britain, Allen \& Unwin, London.

McColl, B., L. Pietsch and J. Gatenby (2001), 'Household Income, Living Standards and Financial Stress' National Social Policy Conference, Australian Bureau of Statistics, Sydney. 
Moller, S., E. Heber, J. Stephens, D. Bradley and F. Nielsen (2003), 'Determinants of Relative Poverty in Advanced Capitalist Democracies', American Sociological Review 68(1):22-51

Organisation for Economic Co-operation and Development (2001), 'When Money is Tight: Poverty Dynamics in OECD Countries', Employment Outlook, Paris.

Oxley, H., J. Burniaux, T. Dang and M. d'Ercole, M. (1997), 'Income Distribution and Poverty in 13 OECD Countries', OECD Economic Studies 29(II):55-94.

Oxley, H., T. Dang and P. Antolin (2000), 'Poverty Dynamics in Six OECD Countries', OECD Economic Studies 30(1):7-52.

Ross, R. and P. Whiteford, (1992), 'Poverty in 1986: Aboriginal Families with Children', Australian Journal of Social Issues 27(2):91-111.

Saunders, P. (1996), 'Poverty and Deprivation in Australia' Year Book Australia (Cat No. 1301 1996), Special Article, Australian Bureau of Statistics, Canberra.

Saunders, P. (1997), 'Poverty, Choice and Legitimacy', Social Policy Research Centre, University of New South Wales, Sydney.

Saunders, P. (1998), 'Using Budget Standards to Assess the Well-being of Families', Social Policy Research Centre, University of New South Wales, Sydney.

Saunders, P., J. Bradshaw and M. Hirst (2002), 'Using Household Expenditure to Develop an Income Poverty Line', Social Policy and Administration 36(3):217-234.

Saunders, Peter and T. Kayoko (2002), 'Poverty in Australia: Beyond the Rhetoric', Centre for Independent Studies, Sydney.

Travers, P. and S. Richardson (1993), Living Decently: Material Wellbeing in Australia, Oxford University Press, Melbourne.

Tsakloglou, P. and F. Papadopoulos (2002), 'Aggregate Level and Determining Factors of Social Exclusion in twelve European countries', Journal of European Social Policy 12(3):211-225.

Watson, N. (2005), 'HILDA User Manual - Release 3.0', Melbourne Institute of Applied Economic and Social Research, University of Melbourne.

Whelan, C., R. Layte, and B. Maitre (2003), 'Persistent Income Poverty and Deprivation in the European Union: An Analysis of the First three Waves of the European Community Household Panel', Journal of Social Policy 32(1):1-19.

Whelan, C., R. Layte and B, Maitre (2002), 'Multiple Deprivation and Persistent Poverty in the European Union', Journal of European Social Policy 12(2):91-105.

This paper is based on analyses of the data in the unconfidentialised unit record file from the DFCS Household, Income and Labour Dynamics in Australia (HILDA) Survey, which is managed by the Melbourne Institute of Applied Economic and Social Research. The findings and views reported in the paper are those of the author and should not be attributed to either DFCS or the Melbourne Institute. The author thanks Simon Freidin, Nicole Watson, and Diana Warren for their assistance with the preparation of the data used in this paper. 